\title{
ANALISIS FAKTOR RISIKO KEJADIAN INFEKSI SALURAN PERNAPASAN AKUT PADA BALITA DI WILAYAH KERJA UPT. PUSKESMAS MENGWI III TAHUN 2016
}

\author{
I Gde Arya Dhioxa Darmawan*, I Made Sutarga \\ Program Studi Sarjana Kesehatan Masyarakat Fakultas Kedokteran Universitas Udayana \\ Alamat: Jalan PB. Sudirman, Denpasar, Bali 80232
}

\begin{abstract}
ABSTRAK
ISPA adalah penyakit pernafasan akut yang berisiko mengakibatkan kematian pada anak usia balita. Beberapa faktor penyebab ISPA pada balita antara lain, jenis kelamin, status gizi dan imunisasi balita, keadaan fisik rumah, pendidikan ibu balita dan perilaku keluarga. Tujuan dalam penelitian ini adalah untuk mengetahui faktor-faktor yang berisiko menjadi penyebab kejadian ISPA pada balita di wilayah kerja UPT. Puskesmas Mengwi III Badung Bali. Penelitian ini menggunakan studi kasus kontrol berpasangan. Berdasarkan analisis faktor risiko balita yang jenis atap rumahnya tidak memenuhi syarat 2 kali lebih berisiko terkena ISPA. Balita dengan keluarga yang menggunakan anti nyamuk bakar 3 kali lebih berisiko terkena ISPA. Balita dengan keluarga yang menggunakan kayu bakar untuk memasak 7 kali lebih berisiko terkena ISPA. Faktor risiko ISPA pada balita dalam wilayah kerja UPT. Puskesmas Mengwi III adalah jenis atap rumah yang tidak memenuhi syarat, penggunaan anti nyamuk bakar, dan penggunaan kayu bakar untuk memasak.
\end{abstract}

Kata Kunci: ISPA, Balita, Faktor Risiko.

\section{ABSTRACT}

ARI's an acute disease that can lead toddlers to risk of death. Some risk factors for ARI in toddlers are gender, immunization status, nutritional status, physical condition of the home, toddler mother education and family behavior. This study aims to determine what risk factors affect the incidence of ARI on toddlers in UPT. Puskesmas Mengwi III Badung Bali. This study uses matched pair case-control study design. Toddlers whose roof types did not meet the requirements 2 times more risk to get ARI. Toddlers with families who use anti-mosquito coils 3 times more risk to get ARI. Toddlers with families who use firewood for cooking are 7 times more risk to get ARI. Risk factors for ARI on toddlers in there is a types of roof that doesn't meet the requirements, the use of anti-mosquito coils, and the use firewood in cooking activities by family.

Keywords: ARI, Toddlers, Risk Factors.

\section{PENDAHULUAN}

ISPA (Penyakit Infeksi Saluran Pernafasan Akut) berdasarkan WHO (2007) merupakan jenis penyakit yang menginfeksi saluran pernapasan dan merupakan penyakit menular serta termasuk dalam golongan 10 besar penyakit yang sering ditemukan pada negara berkembang termasuk Indonesia.

Faktor-faktor penyebab ISPA dibedakan menjadi faktor intrinsik dan faktor ekstrinik. Faktor intrinsik penyebab ISPA antara lain: jenis kelamin, umur, status gizi, status imunisasi, berat badan lahir rendah (BBLR), pemberian air susu ibu (ASI), dan pemberian vitamin. Faktor ekstrinsik penyebab ISPA antara lain: kepadatan hunian, polusi udara, ventilasi, asap rokok, penggunaan bahan bakar untuk memasak, penggunaan obat nyamuk bakar, serta faktor ibu baik pendidikan, umur, maupun pengetahuan ibu. Perilaku masyarakat Bali yang masih menjalankan tradisi menggunakan kayu bakar sebagai bahan bakar untuk memasak memiliki dampak negatif bagi kesehatan. Penggunaan kayu bakar selama aktivitas memasak, menghasilkan asap dan debu yang dapat menyebabkan gangguan pernafasan termasuk ISPA. Data yang diperoleh Depkes (2012) menunjukkan prevalensi ISPA penyebab utama kematian bayi di Indonesia pada tiga tahun berturutturut yaitu sebesar $32,1 \%$, pada tahun 2009 ; 18,2\%, pada tahun 2010 dan sebesar 38,8\% pada tahun 2011. ISPA merupakan 10 besar 
jenis penyakit pada pasien yang berkunjung ke Puskesmas di Provinsi Bali pada tahun 2013. Peringkat pertama, terdapat 212.984 pasien yang berkunjung mengalami Nasofaringitis acute (common cold), peringkat kelima sebanyak 56.882 pasien mengalami Faringitis acute, dan peringkat ke-sembilan sebanyak 50.336 pasien mengalami penyakit ISPA lainnya. Data kejadian pneumonia pada balita di Bali tahun 2013 sejumlah $22,5 \%$, dan sejumlah $74,46 \%$ kasus pada tahun 2010.

Di tingkat kabupaten/kota, Kabupaten Badung (9,7\%) menjadi kabupaten yang cakupan penemuan kasusnya berada pada peringkat kedua terbawah setelah Kabupaten Jembrana (0,6\%) (Dinkes Provinsi Bali, 2013). Angka penemuan kasus pneumonia ditargetkan sebesar $90 \%$ pada tahun 2013, sedangkan di Kabupaten Badung angka penemuan kasusnya jauh dibawah target tersebut yaitu 9,7\% sehingga sangat perlu untuk ditingkatkan. Jumlah kasus pneumonia yang ditemukan di Kabupaten Badung sebanyak 290 kasus (Dinkes Kabupaten Badung, 2014).

\section{METODE PENELITIAN}

Metode yang digunakan pada penelitian ini adalah metode kuantitatif yang menggunakan rancangan penelitian kasus kontrol berpasangan. Kasus kontrol berpasangan adalah desain penelitian dengan menganalisa ciri populasi (melalui sampel kasus dan kontrol yang dipasangkan menurut tempat tinggal) dengan melakukan penelusuran ke belakang untuk mengetahui gambaran faktor risikonya.

Populasi target yang digunakan dalam penelitian ini adalah balita dan populasi studinya adalah balita di wilayah kerja UPT. Puskesmas Mengwi III tahun 2016. Sampel pada penelitian ini adalah balita dalam wilayah kerja UPT. Puskesmas Mengwi III pada saat dilakukan penelitian sedangkan respondennya adalah orang tua dari balita tersebut. Jumlah sampel menggunakan rumus sebagai berikut:

$$
N_{1}=N_{2}=\frac{(Z \propto+Z \beta)^{2} \pi}{\left(P_{1}-P_{2}\right)^{2}}
$$

Perhitungan sampel dengan persamaan diatas diperoleh jumlah sampel minimal sebesar 36 sampel. dimana nilai kemaknaan 0,05 , power $80 \%$, dan $\pi=0,3$ Proporsi kelompok yang terpapar dan sakit 0,612 dan Proporsi kelompok yang tidak terpapar dan sakit 0,356 (Kristina, 2012).

\section{HASIL}

Berdasarkan hasil penelitian kasus ISPA yang terjadi pada balita dibulan Januari Juni 2016 di wilayah kerja UPT. Puskesmas Mengwi III adalah 126 kasus. Dari 126 kasus tersebut dipilih sejumlah 36 kasus sebagai sampel kasus. Penelitian ini merupakan penelitian kasus kontrol berpasangan, maka dipilih sejumlah 36 sampel kontrol yang dicarikan pasangan sesuai banjar/dusun tempat tinggal.

Analisis faktor risiko dilakukan dengan menggunakan tabel $2 \times 2$ dengan uji $M c$ Nemar dengan nilai $\alpha=0,05$ dengan hipotesis Ho : OR = 1 dan Ha : OR>1. Hasil analisis bivariat faktor risiko menunjukan variabel yang berhubungan meningkatkan risiko ISPA pada balita dalam wilayah kerja UPT. Puskesmas Mengwi III. Data yang diperoleh ditunjukkan pada Tabel 1. 
Tabel 1. Analisis Faktor Risiko ISPA pada Balita di Wilayah Kerja Puskesmas Mengwi III

\begin{tabular}{|c|c|c|c|c|c|}
\hline \multicolumn{2}{|c|}{$\begin{array}{c}\text { Kasus } \\
\text { Faktor Risiko }\end{array}$} & \multicolumn{2}{|c|}{$\begin{array}{c}\text { Kontrol } \\
\text { Faktor Risiko }\end{array}$} & \multirow{2}{*}{$\frac{\text { OR }}{1}$} & \multirow{2}{*}{$\begin{array}{c}\mathbf{9 5} \% \mathrm{CI} \\
0,02-50,40\end{array}$} \\
\hline 1. & Jenis Lantai & $\begin{array}{l}\text { Tidak Memenuhi } \\
\text { Syarat }\end{array}$ & $\begin{array}{l}\text { Memenuhi } \\
\text { Syarat }\end{array}$ & & \\
\hline & $\begin{array}{l}\text { Tidak Memenuhi } \\
\text { Syarat }\end{array}$ & 0 & 0 & & \\
\hline & Memenuhi Syarat & 0 & 36 & & \\
\hline \multirow[t]{3}{*}{2.} & Jenis Dinding & $\begin{array}{l}\text { Tidak Memenuhi } \\
\text { Syarat }\end{array}$ & $\begin{array}{l}\text { Memenuhi } \\
\text { Syarat }\end{array}$ & 1 & $0,02-50,40$ \\
\hline & $\begin{array}{l}\text { Tidak Memenuhi } \\
\text { Syarat }\end{array}$ & 0 & 0 & & \\
\hline & Memenuhi Syarat & 0 & 36 & & \\
\hline \multirow[t]{3}{*}{3.} & Jenis Atap & $\begin{array}{l}\text { Tidak Memenuhi } \\
\text { Syarat }\end{array}$ & $\begin{array}{l}\text { Memenuhi } \\
\text { Syarat }\end{array}$ & 2 & $0,18-22,06$ \\
\hline & $\begin{array}{l}\text { Tidak Memenuhi } \\
\text { Syarat }\end{array}$ & 0 & 2 & & \\
\hline & Memenuhi Syarat & 1 & 33 & & \\
\hline \multirow[t]{3}{*}{4.} & Ventilasi & $\begin{array}{l}\text { Tidak Memenuhi } \\
\text { Syarat }\end{array}$ & $\begin{array}{l}\text { Memenuhi } \\
\text { Syarat }\end{array}$ & 1,17 & $0,39-3,47$ \\
\hline & $\begin{array}{l}\text { Tidak Memenuhi } \\
\text { Syarat }\end{array}$ & 11 & 7 & & \\
\hline & Memenuhi Syarat & 6 & 12 & & \\
\hline \multirow[t]{3}{*}{5.} & Kepadatan Hunian & $\begin{array}{l}\text { Tidak Memenuhi } \\
\text { Syarat }\end{array}$ & $\begin{array}{l}\text { Memenuhi } \\
\text { Syarat }\end{array}$ & 1,13 & $0,43-2,92$ \\
\hline & $\begin{array}{l}\text { Tidak Memenuhi } \\
\text { Syarat }\end{array}$ & 13 & 9 & & \\
\hline & Memenuhi Syarat & 8 & 6 & & \\
\hline \multirow[t]{3}{*}{6.} & $\begin{array}{l}\text { Kebiasaan Merokok } \\
\text { Keluarga }\end{array}$ & Merokok & $\begin{array}{l}\text { Tidak } \\
\text { Merokok }\end{array}$ & 1 & $0,32-3,10$ \\
\hline & Merokok & 16 & 6 & & \\
\hline & Tidak Merokok & 6 & 8 & & \\
\hline \multirow[t]{2}{*}{7.} & $\begin{array}{l}\text { Penggunaan Anti } \\
\text { Nyamuk Bakar } \\
\text { Tidak Memenuhi } \\
\text { Syarat }\end{array}$ & $\begin{array}{l}\text { Tidak Memenuhi } \\
\text { Syarat } \\
0\end{array}$ & $\begin{array}{l}\text { Memenuhi } \\
\text { Syarat } \\
6\end{array}$ & 3 & $0,61-14,86$ \\
\hline & Memenuhi Syarat & 2 & 28 & & \\
\hline \multirow[t]{3}{*}{8.} & $\begin{array}{l}\text { Penggunaan Kayu } \\
\text { Bakar Untuk } \\
\text { Memasak }\end{array}$ & $\begin{array}{l}\text { Tidak Memenuhi } \\
\text { Syarat }\end{array}$ & $\begin{array}{l}\text { Memenuhi } \\
\text { Syarat }\end{array}$ & 7 & $0,36-135,52$ \\
\hline & $\begin{array}{l}\text { Tidak Memenuhi } \\
\text { Syarat }\end{array}$ & 0 & 3 & & \\
\hline & Memenuhi Syarat & 0 & 33 & & \\
\hline \multirow[t]{3}{*}{9.} & Pendidikan Ibu & Rendah & Tinggi & 0,75 & $0,26-2,16$ \\
\hline & Rendah & 5 & 6 & & \\
\hline & Tinggi & 8 & 17 & & \\
\hline
\end{tabular}




\begin{tabular}{lllll}
\hline 10. Status Imunisasi & Tidak Lengkap & Lengkap & 1 & $0,02-50,40$ \\
Tidak Lengkap & 0 & 0 & & \\
Lengkap & 0 & 36 & & \\
11. Status Gizi & Gizi & Gizi Baik & 0,75 & $0,17-4,43$ \\
& $\begin{array}{l}\text { Buruk/Kurang/Lebih } \\
\text { Gizi }\end{array}$ & & & \\
Buruk/Kurang/Lebih & 1 & 3 & & \\
Gizi Baik & 4 & 28 & & \\
\hline
\end{tabular}

\section{DISKUSI}

Berdasarkan analisis faktor risiko terhadap variabel bebas yang diteliti didapatkan variabel faktor risiko penyebab ISPA antara lain: jenis atap, penggunaan anti nyamuk bakar, dan penggunaan kayu bakar untuk memasak. Variabel yang tidak termasuk faktor risiko ISPA di wilayah kerja Puskesmas Mengwi III adalah jenis lantai yang digunakan, jenis dinding rumah, ventilasi, kepadatan hunian rumah, perilaku merokok, pendidikan ibu, status imunisasi dan status gizi.

\section{Faktor Risiko}

Faktor risiko yang pertama adalah jenis atap yang digunakan pada rumah balita yang tidak memenuhi syarat $(\mathrm{OR}=2)$, digolongkan tidak memenuhi syarat jika terbuat dari seng/ asbes serta dalam kondisi yang tidak sempurna (tidak menggunakan langit-langit). Rumah balita yang jenis atap rumahnya tidak memenuhi syarat memiliki risiko terkena ISPA 2 kali lipat dari pada balita yang atap rumahnya terbuat dari genting/seng yang dilengkapi dengan langitlangit (tergolong dalam atap rumah memenuhi syarat).

Faktor risiko yang kedua adalah penggunaan anti nyamuk ( $\mathrm{OR}=3)$, digolongkan berisiko jika menggunakan anti nyamuk bakar dalam keseharian di rumah. Balita dengan keluarga yang menggunakan anti nyamuk bakar memiliki risiko terkena
ISPA 3 kali lebih besar jika dibandingkan dengan balita yang menggunakan anti nyamuk semprot atau lotion atau kelambu.

Faktor risiko yang ketiga adalah bahan bakar memasak (OR=7). Bahan bakar untuk memasak digolongkan berisiko jika yang digunakan adalah kayu bakar. Penggunaan kayu bakar untuk memasak oleh keluarga balita berisiko terkena ISPA 7 kali lebih besar dari pada balita dengan keluarga yang menggunakan gas/listrik sebagai bahan bakar untuk memasak.

\section{Bukan Faktor Risiko}

Variabel bebas yang diteliti yang bukan faktor risiko penyebab terjadinya kasus ISPA pada balita di wilayah kerja UPT. Puskesmas Mengwi III adalah jenis lantai $(\mathrm{OR}=1)$, jenis dinding $(\mathrm{OR}=1)$, ventilasi $(\mathrm{OR}=1,17)$, kepadatan hunian $(\mathrm{OR}=1,13)$, perilaku merokok $(\mathrm{OR}=1)$, pendidikan ibu $(\mathrm{OR}=0,75)$, status imunisasi $(\mathrm{OR}=1)$ dan status gizi (OR=0,75).

Hal itu terjadi kemungkinan karena jumlah sampel yang kurang atau karena sudah bagusnya lingkungan fisik rumah masyarakat dalam wilayah kerja UPT. Puskesmas Mengwi III.

\section{Keterbatasan Penelitian}

Kasus kontrol berpasangan yang digunakan dalam penelitian memiliki kelemahan untuk pengendalian recall bias yang sering terjadi saat wawancara dengan nara sumber. Rentang kesalahan akibat recall 
bias dapat diminimalisir dengan melibatkan anggota keluarga lain saat pengambilan data, serta didukung dengan bukti/ keterangan instansi kesehatan dan menentukan subyek terbaru yang didiagnosis oleh puskesmas. Jumlah penemuan kasus ISPA di wilayah kerja UPT. Puskesmas Mengwi III tidak memenuhi target jumlah sampel, sehingga jumlah sampel harus dipangkas sangat signifikan dan dapat mempengaruhi hasil analisis. Penelitian dilakukan terbatas pada satu puskesmas, sehingga tidak dapat mewakili karakteristik wilayah kerja puskesmas lain di wilayah Kabupaten Badung.

\section{SIMPULAN}

Berdasarkan analisis faktor risiko terhadap variabel bebas yang diteliti dapat disimpulkan variabel yang merupakan faktor-faktor yang menyebabkan kejadian ISPA pada balita di wilayah kerja UPT. Puskesmas Mengwi III yaitu atap yang digunakan pada rumah balita $(\mathrm{OR}=2)$, anti nyamuk bakar yang digunakan $(\mathrm{OR}=3)$, dan penggunaan kayu bakar saat memasak (OR=7).

Variabel yang tidak termasuk faktor risiko ISPA di wilayah kerja UPT. Puskesmas Mengwi III adalah jenis lantai $(\mathrm{OR}=1)$, jenis dinding $(\mathrm{OR}=1)$, ventilasi $(\mathrm{OR}=1,17)$, kepadatan hunian $(\mathrm{OR}=1,13)$, perilaku merokok $(\mathrm{OR}=1)$, pendidikan ibu $(\mathrm{OR}=0,75)$, status imunisasi $(\mathrm{OR}=1)$ dan status gizi $(\mathrm{OR}=0,75)$.

\section{SARAN}

Bagi UPT. Puskesmas Mengwi III agar meningkatkan upaya temuan kasus ISPA di masyarakat baik secara aktif dilapangan maupun pasif di puskesmas. Selain itu juga melakukan penyebaran informasi mengenai ISPA dan cara pencegahannya pada balita lewat Posyandu.

Bagi peneliti selanjutnya agar dapat mengetahui lebih jelas gambaran faktor risiko ISPA diharapkan menambah jumlah variabel dan sampel penelitian.

\section{UCAPAN TERIMAKASIH}

Ucapan terimakasih penulis sampaikan kepada Universitas Udayana, UPT. Puskesmas Mengwi III, serta semua pihak yang berkontribusi pada penelitian ini.

\section{DAFTAR PUSTAKA}

Dinkes Kabupaten Badung 2014, Profil Kesehatan Kabupaten Badung Tahun 2014, Dinkes Kabupaten Badung , Badung

Dinkes Provinsi Bali 2013, Profil Kesehatan Provinsi Bali Tahun 2013, Dinkes Provinsi Bali, Denpasar

Depkes RI 2012, Pedoman Pengendalian Infeksi Saluran Pernapasan Akut, Kementerian Kesehatan RI, Jakarta

Kristina Sinaga, E. R. 2012, Kualitas Lingkungan Fisik Rumah Dengan Kejadian Infeksi Saluran Pernapasan Akut (ISPA) Pada Balita Di Wilayah Kerja Puskesmas Kelurahan Warakas Kecamatan Tanjung Priok Jakarta Utara Tahun 2012, FKM Universitas Indonesia, Jakarta

WHO 2007, Pencegahan \& Pengendalian Infeksi Saluran Pernafaasan Akut (ISPA) yang Cenderung Menjadi Epidemic \& Pandemic Di Fasilitas Pelayanan Kesehatan, WHO 